\title{
Does obstructive sleep apnoea influence BNP concentrations in atrial fibrillation patients?
}

\author{
Anna E. Platek, Alicja Dudzik-Plocica, Karolina Semczuk, Dariusz Gorko, Anna Rys, Marcin Kotkowski, \\ Filip M. Szymanski, Krzysztof J. Filipiak
}

$1^{\text {st }}$ Department of Cardiology, Medical University of Warsaw, Poland

\begin{abstract}
Summary
Background B-type natriuretic peptide (BNP) is a biomarker commonly used in diagnosing and assessing prognosis in heart failure patients. Its concentration can be elevated in various conditions associated with excessive heart wall stretch including atrial fibrillation and obstructive sleep apnoea (OSA). The aim of the study was to assess if BNP levels in atrial fibrillation patients are associated with the value of apnoea-hypopnea index (AHI).

Material and methods Study population were consecutive patients with atrial fibrillation, who underwent overnight sleep study, and had blood taken for BNP concentration assessment. Subsequently, patients were divided into group according to AHI: Group I ( $<5 / \mathrm{h})$, Group II $(5-15 / \mathrm{h})$, and Group III ( $>15 / \mathrm{h})$.

Results: Analysis covered 158 patients (males, 64.6\%; mean age, $58.3 \pm 9.2$ years). 83 (52.5\%) patients had AHI $<5 / \mathrm{h}$, Group II consisted of 44 (27.9\%), and Group III of 31 (19.6\%) patients. Mean BMI and neck circumference rose with AHI value severity. BMI was as follows $28.7 \pm 4.3,30.7 \pm 4.7$, and $31.8 \pm 5.2 \mathrm{~kg} / \mathrm{m} 2$ ( $\mathrm{p}$ for trend $<0.01$ ), while neck circumference was $39.2 \pm 3.5,41.5 \pm 3.9$, and $41.2 \pm 3.2 \mathrm{~cm}$, (p for trend $=0.001$ ) for Group I, II, and III respectively. BNP concentration was the lowest in Group I $(53.0 \pm 57.0 \mathrm{pg} / \mathrm{mL})$, in middle ranges in Group II $(69.2 \pm 89.9 \mathrm{pg} / \mathrm{mL})$, and the highest in patients with AHI $>15(104.0 \pm 150.8 \mathrm{pg} / \mathrm{mL} ; \mathrm{p}$ for trend $=0.03)$.

Conclusions Majority of patients with atrial fibrillation have AHI $<5 / \mathrm{h}$ and these generally have lower BMI, and neck circumference. Patients who have AHI exceeding $\geq 5 / \mathrm{h} B N P$ levels tend to be elevated, and its values rise along with AHI.
\end{abstract}

key words: B-type natriuretic peptide; atrial fibrillation; obstructive sleep apnoea

Arterial Hypertens. 2015, vol. 19, no. 4, pages: 179-186

DOI: $10.5603 / A H .2015 .0022$

\section{Background}

Physicians constantly seek to find non-invasive, widely applicable screening and diagnostic methods. Hopes in this field are associated with a use of various biomarkers. Myoglobin, CK-MB (creatine kinase $\mathrm{MB})$, D-dimer, or especially troponins have been excessively studied, and had shown to be a useful clinical tool, predictive for prognosis in various clinical conditions [1-4]. Today we almost cannot imagine clinical practice without biomarkers, like troponin in diagnosis of myocardial infarction, or D-dimer in ruling out pulmonary embolism, and next biomarkers still are undergoing excessive studies for their clinical utility $[5,6]$. B-type natriuretic peptide (BNP) and its $\mathrm{N}$-terminal prohormone (NT-proBNP) are currently widely used in diagnosing and predicting long-term prognosis in heart failure and myocardial infarction patients $[7,8]$. BNP is produced in response to non-specific pressure overload of heart chambers, and therefore is a marker, found to be elevated not only in heart failure, but also in other con-

Address for correspondence: Filip M. Szymanski, MD, PhD

1A Banacha Street, 02-097 Warsaw, Poland

e-mail: filip.szymanski@wum.edu.pl

VM Copyright (c 2015 Via Medica, ISSN 2449-6170 
ditions associated with raise in intracardiac pressure such as arterial and pulmonary hypertension, valvular heart disease, atrial fibrillation, and even non-cardiac disease including pulmonary and renal disorders [9]. For some of the conditions mentioned above BNP will have limited utility in diagnostics, but as a predictor of heart involvement, therefore its remodelling and long-term outcome, BNP levels will be crucial. This applies especially to situations where number of conditions influencing heart haemodynamics coexists in one patient. Those conditions include i.e. atrial fibrillation and repetitive apnoea and hypopnoea episodes associated with obstructive sleep apnoea (OSA). The aim of the study was to establish if alterations in BNP profile in atrial fibrillation patients are associated with the number of apnoea and hypopnoea episodes measured in apnoea-hypopnoea index (AHI).

\section{Material and methods}

\section{Study population}

The study protocol was approved by the Regional Ethics Committee and a written informed consent was obtained from every patient. Study population consisted of 163 consecutive patients hospitalized due to persistent or paroxysmal atrial fibrillation in a tertiary, Cardiology Department of a high-volume University Teaching Hospital. Primary indication for the hospitalization was pre-qualification for future ablation for atrial fibrillation, in patients with at least one episode of the arrhythmia documented in a 24-hour Holter ECG monitoring during 6 months prior to the enrolment. We included in the study patients with atrial fibrillation documented in at least one 24-hour ECG Holter examination performed in 6 months prior to the enrolment, who gave written informed consent. Patients with diagnosed heart failure or with clinical signs of heart failure in the initial examination, at the age of $<18$ or $\geq 75$ years, who underwent ablation for atrial fibrillation in the past, suffered from myocardial infarction, or stroke within last 6 months, with untreated significant hyper- or hypothyroidism, or currently undergoing treatment with continuous positive airway pressure were excluded from the study. According to the study protocol, apart from medical examination standard for atrial fibrillation, all patients underwent an over-night sleep study and had their BNP level measured.

Atrial fibrillation was defined as paroxysmal or persistent according to 2010 and 2012 guidelines of the European Society of Cardiology. Paroxysmal AF was defined as a self-terminating, usually within $48 \mathrm{~h}$, which may continue for up to 7 days. Persistent AF was defined when AF episode either lasted longer than 7 days or required termination by cardioversion, either with drugs or by direct current cardioversion $[10,11]$.

\section{Sleep study}

During the night following admission all patients underwent an overnight polygraphy sleep study using a portable device for diagnosing of sleep disorders (Embletta X30; Flaga, Reykjavik, Iceland), a level 3 sleep monitoring tool (according to the European Respiratory Society and the European Society of Hypertension recommendations for sleep-disordered breathing management in cardiac patients), with $>4$ channels including channels to detect respiratory movements or respiratory effort, airflow, heart rate, ECG, and oxygen saturation [12]. Every study was evaluated and scored manually by an experienced physician qualified in sleep medicine, according to the recommendations of the American Academy of Sleep Medicine [13]. Definition of apnoea was a cessation of airflow lasting $\geq 10$ seconds, while hypopnea was defined as a recognizable transient reduction (but not complete cessation) of breathing for 10 seconds or longer with a reduction in air flow amplitude of more than $30 \%$ associated with following oxygen desaturation of $\geq 3 \%$. Total desaturation time was calculated basing on time period during which blood oxygen saturation was $<90 \%$. All patients were also screened for symptoms of excessive daytime sleepiness using the Epworth Sleepiness Scale, with a cut-off value for diagnosis of $>10$ points. Elevated AHI value was considered $\geq 15$ per hour irrespectively of the daytime symptoms. Patients were also divided into groups according to the AHI value: to the group with $\mathrm{AHI}<5$ per hour (Group I), AHI between 5 and 15 per hour (Group II) and AHI of > 15 per hour (Group III).

\section{BNP analysis}

BNP was measured in a $10 \mathrm{~mL}$ whole venous blood sample taken in the morning in supine position, to a tube containing EDTA. Blood samples were immediately analysed using Triage BNP Test (Biosite Diagnostics, La Jolla, CA, USA). Triage ${ }^{\bullet}$ BNP Test is a commercially available fluorescence immunoassay for the BNP quantification. It is a portable kit designed for quick, bedside BNP analysis. It has been validated in in vitro, as well as clinical studies, with an assay analytical sensitivity of less than $1.4 \mathrm{pmol} / \mathrm{L}[14,15]$. Manufacturer provided cut-off point suggestive of patients with congestive heart failure is $>100 \mathrm{pg} / \mathrm{mL}$.

\section{Statistical analysis}

Continuous data are presented as mean \pm standard deviation (SD) and were compared using the 


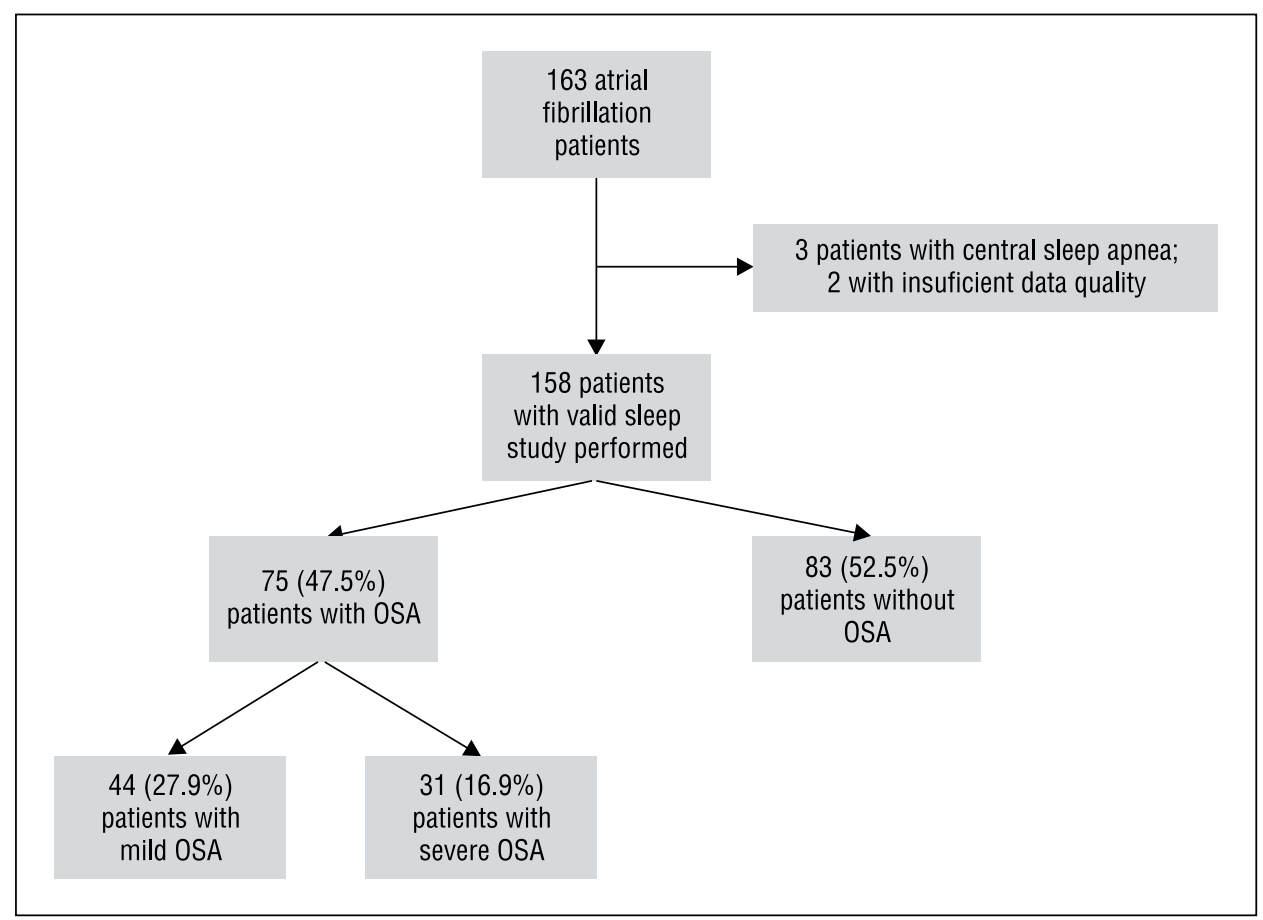

Figure 1. Study design

Mann-Whitney test or Student's t-test. Categorical variables were compared using either the Chi-square or Fisher exact tests. A p value of less than 0.05 was considered statistically significant, whereas the confidence intervals $(\mathrm{CI})$ were $95 \%$. A one-way analysis of variance was used to assess the impact of OSA severity according to AHI on the BNP levels. Statistical analyses were performed using SAS statistical software version 8.02 (SAS Institute, Inc., Cary, NC, USA).

\section{Results}

Final analysis covered 158 patients (males, 64.6\%; mean age, $58.3 \pm 9.2$ years), 3 patients were excluded from the study due to central sleep apnoea. In two cases quality of polygraphy results and/or BNP measurement was insufficient for further analysis (Figure 1). In the study population mean body mass index (BMI) meeting criteria for overweight was noticeable (29.9 $\left.\pm 4.8 \mathrm{~kg} / \mathrm{m}^{2}\right)$. Patients also had large neck and waist circumference $(40.2 \pm 3.7 \mathrm{~cm}$ and $110.7 \pm 81.6 \mathrm{~cm}$, respectively). General co-morbidity in the study population was not high, except for hypertension, which was present in $74.1 \%$ and dyslipidaemia in $59.5 \%$ of participants. Despite high prevalence of diagnosed hypertension, mean systolic and diastolic blood pressure (SBP and DBP) values on admission were $132.9 \pm 16.6 \mathrm{~mm} \mathrm{Hg}$ and $81.0 \pm 11.4 \mathrm{~mm} \mathrm{Hg}$, respectively (Table I).
Table I. Baseline characteristics of the study population

\begin{tabular}{|c|c|}
\hline Parameter & Mean \pm SD or $n(\%)$ \\
\hline Male sex; $n(\%)$ & $102(64.6 \%)$ \\
\hline Age (years) & $58.3 \pm 9.2$ \\
\hline Height [cm] & $171.9 \pm 10.1$ \\
\hline Weight [kg] & $88.3 \pm 16.1$ \\
\hline Body Mass Index $\left[\mathrm{kg} / \mathrm{m}^{2}\right]$ & $29.9 \pm 4.8$ \\
\hline Neck circumference $[\mathrm{cm}]$ & $40.2 \pm 3.7$ \\
\hline Waist circumference [cm] & $110.7 \pm 81.6$ \\
\hline $\mathrm{SBP}[\mathrm{mm} \mathrm{Hg}]$ & $132.9 \pm 16.6$ \\
\hline $\mathrm{DBP}[\mathrm{mm} \mathrm{Hg}]$ & $81.0 \pm 11.4$ \\
\hline HR (beats per min) & $74.1 \pm 14.6$ \\
\hline Prior myocardial infarction; n(\%) & $15(9.5 \%)$ \\
\hline Diabetes mellitus; $n(\%)$ & $10(6.3 \%)$ \\
\hline Hypertension; $n(\%)$ & $117(74.1 \%)$ \\
\hline Gout; $n(\%)$ & $8(5.1 \%)$ \\
\hline Smoking; $n(\%)$ & $17(10.8 \%)$ \\
\hline Alcohol consumption; n(\%) & $15(9.5 \%)$ \\
\hline Prior stroke; $\mathrm{n}(\%)$ & $16(10.1 \%)$ \\
\hline Peptic ulcer disease; n(\%) & $21(13.3 \%)$ \\
\hline Dyslipidaemia; $\mathrm{n}(\%)$ & $94(59.5 \%)$ \\
\hline Thyroid disease; $n(\%)$ & $41(25.9 \%)$ \\
\hline Family history of CVD; $n(\%)$ & $61(38.6 \%)$ \\
\hline Paroxysmal AF; n(\%) & $110(69.9 \%)$ \\
\hline BNP $[\mathrm{pg} / \mathrm{mL}]$ & $67.5 \pm 92.9$ \\
\hline
\end{tabular}


Table II. Comparison of patients with and without obstructive sleep apnoea (OSA)

\begin{tabular}{|c|c|c|c|}
\hline Parameter; mean \pm SD or $n(\%)$ & $\begin{array}{c}O S A(A H I \geq 15 / h) \\
(n=32)\end{array}$ & $\begin{array}{c}\text { No OSA (AHI < 15/h) } \\
(n=126)\end{array}$ & $\mathrm{p}$ value \\
\hline AHI (per hour) & $24.4 \pm 10.1$ & $4.5 \pm 3.7$ & - \\
\hline Lowest $\mathrm{SpO}_{2}(\%)$ & $79.7 \pm 7.3$ & $85.5 \pm 5.4$ & $<0.0001$ \\
\hline Male sex; $n(\%)$ & $20(62.5 \%)$ & $82(65.1 \%)$ & 0.95 \\
\hline Age (years) & $60.3 \pm 7.3$ & $57.8 \pm 9.5$ & 0.19 \\
\hline Height $[\mathrm{cm}]$ & $172.7 \pm 11.1$ & $171.5 \pm 9.9$ & 0.61 \\
\hline Weight [kg] & $94.5 \pm 14.2$ & $86.7 \pm 16.2$ & 0.01 \\
\hline Body Mass Index $\left[\mathrm{kg} / \mathrm{m}^{2}\right]$ & $31.8 \pm 5.1$ & $29.4 \pm 4.6$ & 0.008 \\
\hline Neck circumference $[\mathrm{cm}]$ & $41.1 \pm 3.2$ & $40.0 \pm 3.8$ & 0.14 \\
\hline Waist circumference [cm] & $109.0 \pm 10.9$ & $103.1 \pm 12.4$ & 0.02 \\
\hline $\mathrm{SBP}[\mathrm{mm} \mathrm{Hg}]$ & $133.9 \pm 17.3$ & $132.6 \pm 16.5$ & 0.71 \\
\hline $\mathrm{DBP}[\mathrm{mm} \mathrm{Hg}]$ & $81.3 \pm 13.2$ & $80.9 \pm 11.0$ & 0.87 \\
\hline HR (beats per min) & $75.5 \pm 13.9$ & $73.7 \pm 14.8$ & 0.53 \\
\hline Prior Ml; $\mathrm{n}(\%)$ & $4(12.5 \%)$ & $11(8.7 \%)$ & 0.76 \\
\hline Diabetes mellitus; $n(\%)$ & $4(12.5 \%)$ & $6(4.8 \%)$ & 0.23 \\
\hline Hypertension; $n(\%)$ & $26(81.3 \%)$ & $91(72.2 \%)$ & 0.42 \\
\hline Gout; $n(\%)$ & $0(0.0 \%)$ & $8(6.3 \%)$ & 0.31 \\
\hline Smoking; $n(\%)$ & $2(6.3 \%)$ & $15(11.9 \%)$ & 0.55 \\
\hline Alcohol consumption; n(\%) & $6(18.8 \%)$ & $9(7.1 \%)$ & 0.1 \\
\hline Prior stroke; $n(\%)$ & $4(12.4 \%)$ & $12(9.5 \%)$ & 0.86 \\
\hline Dyslipidaemia; $n(\%)$ & $21(65.6 \%)$ & $73(57.9 \%)$ & 0.56 \\
\hline Thyroid disease; $n(\%)$ & $6(18.8 \%)$ & $35(27.8 \%)$ & 0.42 \\
\hline Family history of CVD; $n(\%)$ & $13(40.6 \%)$ & $48(38.1 \%)$ & 0.92 \\
\hline $\mathrm{BNP}[\mathrm{pg} / \mathrm{mL}]$ & $101.8 \pm 148.8$ & $58.7 \pm 70.3$ & 0.04 \\
\hline
\end{tabular}

$\mathrm{SD}$ — standard deviation; OSA — obstructive sleep apnoea; Lowest $\mathrm{SpO}_{2}$ — lowest registered blood oxygen saturation; SBP — systolic blood pressure; DBP — diastolic blood pressure; $\mathrm{HR}$ — heart rate; $\mathrm{MI}$ — myocardial infarction; CVD — cardiovascular disease; AF — atrial fibrillation; BNP — B-type natriuretic peptide

Sleep study results revealed that elevated AHI values $(\geq 15$ per hour) were present in $20.3 \%$ of the study population. Patients with the elevated number of sleep disturbance episodes were more likely to have higher BMI $\left(31.8 \pm 5.1\right.$ vs. $29.4 \pm 4.6 \mathrm{~kg} / \mathrm{m}^{2}$; $\mathrm{p}=0.008)$, and waist circumference $(109.0 \pm 10.9$ vs. $103.1 \pm 12.4 \mathrm{~cm} ; \mathrm{p}=0.02)$. No significant differences were noticed regarding prevalence of co-morbidities, including hypertension, dyslipidaemia, diabetes, and history of vascular events. Parameters of the sleep study results showed that mean AHI in group with AHI $\geq 15$ per hour was $24.4 \pm 10.1$ per hour, and $4.5 \pm 3.7$ per hours in the other group. BNP levels were markedly higher in patients with $\mathrm{AHI} \geq 15$ per hour $(101.8 \pm 148.8$ vs. $58.7 \pm 70.3 \mathrm{pg} / \mathrm{mL}$; $\mathrm{p}=0.04$ ) (Table II). Symptoms of excessive day-time sleepiness were present in approximately $36.8 \%$ of patients with elevated AHI.

Dividing patients into groups with $\mathrm{AHI}<5$ per hour (Group I), AHI between 5 and 15 per hour
(Group II) and AHI of > 15 per hour (Group III) showed additional differences presented in detail in Table III. Group I consisted of $83(52.5 \%)$ patients, Group II of 44 (27.9\%) patients, and Group III of $31(19.6 \%)$ patients. As predicted, a trend towards worst oxymetry parameters with rising AHI values was noticeable. Mean AHI for Group I was $2.2 \pm 1.4$ per hour, $9.1 \pm 2.7$ per hour for Group II, and 24.6 \pm 10.2 per hour for Group III. Mean blood oxygen saturation was $94.2 \pm 1.8$ vs. $93.1 \pm 1.5$ vs. $93.4 \pm$ $1.8 \%$ ( $\mathrm{p}$ for trend $<0.01$ ), total percent time in desaturation was $2.5 \pm 9.2$ vs. $4.6 \pm 7.1$ vs. $7.7 \pm 9.3 \%$ (p for trend 0.03), and lowest registered saturation was $86.4 \pm 5.5$ vs. $83.3 \pm 4.9$ vs. $79.9 \pm 7.4$, respectively ( $\mathrm{p}$ for trend $<0.001$ ).

Other significant differences were noticed in terms of anthropometric features. Mean weight, BMI and neck circumference also rose with AHI values. Mean weight was equal $84.2 \pm 15.2,91.4 \pm 17.0$, and 95.0 $\pm 14.1 \mathrm{~kg}$ for Group I, Group II, and Group III 
Table III. Differences between the groups according to obstructive sleep apnoea (OSA) severity

\begin{tabular}{|c|c|c|c|c|}
\hline Parameter; mean \pm SD or $n(\%)$ & $\begin{array}{c}\text { Non-0SA } \\
\text { AHI }<5 / \mathrm{h}(n=83)\end{array}$ & $\begin{array}{c}\text { Mild OSA } \\
\text { AHI 5-15/h }(\mathrm{n}=44)\end{array}$ & $\begin{array}{l}\text { Severe OSA } \\
\begin{array}{c}\text { AHI }>15 / h \\
(n=31)\end{array}\end{array}$ & $\begin{array}{l}p \text { value } \\
\text { for trend }\end{array}$ \\
\hline AHI (per hour) & $2.2 \pm 1.4$ & $9.1 \pm 2.7$ & $24.6 \pm 10.2$ & - \\
\hline Mean $\mathrm{SpO}_{2}(\%)$ & $94.2 \pm 1.8$ & $93.1 \pm 1.5$ & $93.4 \pm 1.8$ & $<0.01$ \\
\hline Total desaturation time [min] & $8.6 \pm 29.1$ & $18.2 \pm 28.1$ & $31.2 \pm 35.0$ & $<0.01$ \\
\hline Lowest $\mathrm{SpO}_{2}(\%)$ & $86.4 \pm 5.5$ & $83.3 \pm 4.9$ & $79.9 \pm 7.4$ & $<0.001$ \\
\hline Male sex; $n(\%)$ & $47(56.6 \%)$ & $35(79.5 \%)$ & $20(64.5 \%)$ & 0.16 \\
\hline Age (years) & $57.5 \pm 10.4$ & $58.6 \pm 7.7$ & $60.1 \pm 7.4$ & 0.37 \\
\hline Height $[\mathrm{cm}]$ & $171.1 \pm 10.7$ & $172.5 \pm 8.6$ & $173.2 \pm 10.9$ & 0.54 \\
\hline Weight $[\mathrm{kg}]$ & $84.2 \pm 15.2$ & $91.4 \pm 17.0$ & $95.0 \pm 14.1$ & $<0.01$ \\
\hline Body Mass Index [kg/m²] & $28.7 \pm 4.3$ & $30.7 \pm 4.7$ & $31.8 \pm 5.2$ & $<0.01$ \\
\hline Neck circumference $[\mathrm{cm}]$ & $39.2 \pm 3.5$ & $41.5 \pm 3.9$ & $41.2 \pm 3.2$ & 0.001 \\
\hline Waist circumference [cm] & $112.6 \pm 111.6$ & $108.0 \pm 11.7$ & $109.4 \pm 10.8$ & 0.95 \\
\hline $\mathrm{SBP}[\mathrm{mm} \mathrm{Hg}]$ & $132.6 \pm 16.3$ & $133.1 \pm 17.1$ & $133.3 \pm 17.3$ & 0.98 \\
\hline $\mathrm{DBP}[\mathrm{mm} \mathrm{Hg}]$ & $79.7 \pm 10.6$ & $83.3 \pm 11.2$ & $81.0 \pm 13.3$ & 0.24 \\
\hline HR (beats per min) & $72.7 \pm 12.7$ & $75.3 \pm 18.1$ & $76.0 \pm 13.9$ & 0.46 \\
\hline Prior Ml; $n(\%)$ & $8(9.6 \%)$ & $3(6.8 \%)$ & $4(12.9 \%)$ & 0.75 \\
\hline Diabetes mellitus; $n(\%)$ & $4(4.8 \%)$ & $2(4.5 \%)$ & $4(12.9 \%)$ & 0.17 \\
\hline Hypertension; $n(\%)$ & $58(69.9 \%)$ & $34(77.3 \%)$ & $25(80.6 \%)$ & 0.20 \\
\hline Gout; $n(\%)$ & $4(4.8 \%)$ & $4(9.1 \%)$ & $0(0.0 \%)$ & 0.53 \\
\hline Smoking; $n(\%)$ & $11(13.3 \%)$ & $4(9.1 \%)$ & $2(6.5 \%)$ & 0.26 \\
\hline Alcohol consumption; $n(\%)$ & $5(6.0 \%)$ & $4(9.1 \%)$ & $6(19.4 \%)$ & 0.04 \\
\hline Prior stroke; $n(\%)$ & $8(9.6 \%)$ & $4(9.1 \%)$ & $4(12.9 \%)$ & 0.67 \\
\hline Peptic ulcer disease; $\mathrm{n}(\%)$ & $11(13.3 \%)$ & $9(20.5 \%)$ & $1(3.2 \%)$ & 0.36 \\
\hline Dyslipidaemia; $n(\%)$ & $50(60.2 \%)$ & $24(54.5 \%)$ & $20(64.5 \%)$ & 0.85 \\
\hline Thyroid disease; $n(\%)$ & $24(28.9 \%)$ & $12(27.3 \%)$ & $5(16.1 \%)$ & 0.20 \\
\hline Family history of CVD; $n(\%)$ & $33(39.8 \%)$ & $15(34.1 \%)$ & $13(41.9 \%)$ & 0.81 \\
\hline BNP $[p g / m L]$ & $53.0 \pm 57.0$ & $69.2 \pm 89.9$ & $104.0 \pm 150.8$ & 0.03 \\
\hline
\end{tabular}

No OSA — patients with apnoea-hypopnoea $<5$ per hour

Mild OSA — patients with apnoea-hypopnoea index $5-15$ per hour

Severe OSA - patients with apnoea-hypopnea index $>15$ per hou

$\mathrm{SD}$ - standard deviation; OSA - obstructive sleep apnoea; Lowest $\mathrm{SpO}_{2}$ - lowest registered blood oxygen saturation; Total desaturation time - time of blood oxygen saturation $<90 \%$; $\mathrm{SBP}$ - systolic blood pressure; DBP — diastolic blood pressure; $\mathrm{HR}$ - heart rate; $\mathrm{MI}$ - myocardial infarction; CVD — cardiovascular disease; AF — atrial fibrillation; BNP — B-type natriuretic peptide

patients respectively $(\mathrm{p}$ for trend $<0.01$ ). BMI for respective groups was as follows $28.7 \pm 4.3,30.7 \pm$ 4.7 , and $31.8 \pm 5.2 \mathrm{~kg} / \mathrm{m}^{2}$ ( $\mathrm{p}$ for trend $<0.01$ ), while neck circumference was $39.2 \pm 3.5,41.5 \pm 3.9$, and $41.2 \pm 3.2 \mathrm{~cm}$, respectively ( $\mathrm{p}$ for trend $=0.001$ ).

BNP also showed positive correlation with AHI values. Its concentration was the lowest in Group I $(53.0 \pm 57.0 \mathrm{pg} / \mathrm{mL})$, in middle value ranges in mild Group II $(69.2 \pm 89.9 \mathrm{pg} / \mathrm{mL})$, and the highest in Group III $(104.0 \pm 150.8 \mathrm{pg} / \mathrm{mL}$; $\mathrm{p}$ for trend $=$ 0.03) (Figure 2).

Applying different thresholds AHI (including forming groups with AHI 15-30 per hour and $\geq$

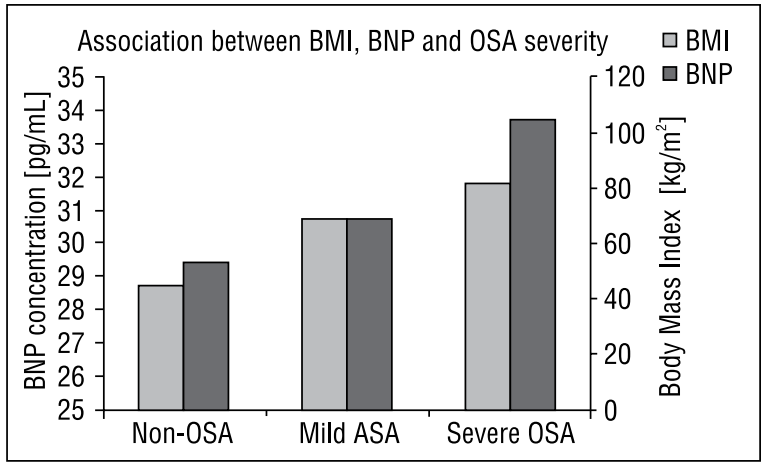

Figure 2. Association between body mass index, B-type natriuretic peptide and obstructive sleep apnea severity 
30 per hour) did not show for the observed trend to continue. After exceeding cut off point of AHI > 15, mean BNP concentrations for rising AHI groups did not show to be statistically higher.

\section{Discussion}

Both, atrial fibrillation and sleep disturbances, including OSA are diseases highly prevalent in the general population, with prevalence estimated to be approximately $2 \%$ and rising with age, even up to $15 \%$ in 80 -year-old for atrial fibrillation, and prevalence of OSA being $24 \%$ and $9 \%$ for men and women respectively [16-18]. OSA prevalence in the general population of atrial fibrillation patients is estimated to be between from 32 and 49\% [19]. Due to their common pathophysiology, and often coexistence, atrial fibrillation and OSA were even previously described to be a part of a clinical syndrome [20].

In atrial fibrillation patients, as well as in the general population, occurrence of sleep disordered breathing associated with apnoeas and hypopneas, is correlated with factors such as older age, higher BMI, and therefore larger waist circumference and neck circumference [19]. In present study, prevalence of patients with elevated AHI values and factors associated with their occurrence were similar to data in the literature. We showed that, AHI values of $\geq 5$ per hour were present in $47.5 \%$ of the study group, and associated with older age and higher BMI than in patients without the sleep-disordered breathing.

Currently, there are no biomarkers specific only for atrial fibrillation, but many different substances were tested for their clinical utility in this condition [21]. Cardiac troponins which are specific for myocardial necrosis, and are released during injury to the cardiac muscle have also been studied in settings of atrial fibrillation condition. Troponins in circulating blood of atrial fibrillation patients were shown to be a predictor of worse outcome. Patients with higher troponin concentration are more likely to have major cardiac and/or cerebrovascular events and have higher mortality rates $[22,23]$. Other biomarkers like inflammatory markers and various adipokines have also been studied. High levels of C-reactive protein (CRP), the most widely used biomarker linked to inflammation, demonstrated to be predictive for increased risk for developing atrial fibrillation [24]. Further studies also revealed its association with composite end-point of stroke and death, or composite of ischaemic stroke, myocardial infarction and vascular death $[25,26]$. Markers of thrombosis and fibrinolysis, including $\mathrm{D}$-dimer and $\beta$-thromboglobulin, were predictors of hypercoagulability, and therefore their elevated levels correlated with the risk of thromboembolism (including stroke and systemic thromboembolism) [27]. Also platelet function parameters and markers of endothelial dysfunction were also altered in patients with atrial fibrillation [21]. Conflicting data on the association between the BNP concentrations and atrial fibrillation may be found in the literature, but most of the studies seem to show that elevated BNP levels are associated with higher risk of new-onset atrial fibrillation and NT-proBNP is predictive of thromboembolic risk, stroke and cardiovascular mortality [23, 28, 29].

Although limited data is available, studies show different results regarding BNP levels and its clinical utility in patients with sleep disordered-breathing. Most of the studies base on small samples of symptomatic OSA patients. Many of available data focus mostly on BNP variations during the nighttime. One of the studies showed nocturnal variations in BNP levels, with a peak between 2:00 and 6:00 AM in patients with OSA, which was reduced, if patient used continuous positive airway pressure (CPAP) therapy [30]. In other studies, conducted in women with OSA, a correlation between sleep disordered breathing severity and BNP levels was found [31, 32]. Contrary, other investigators reported no alterations of BNP profile in patients with OSA, and also found a lack of its correlation with OSA treatment [33,34]. In present study, we showed that the disease severity measured by $\mathrm{AHI}$ was associated with increase in BNP level. Patients with AHI > 15 per hour, here defined as severe OSA, during the nighttime undergo constant, repetitive disruptions in ventilation followed by microarousals, much more frequently than patients with lower AHI (mild OSA) or free from the disease. To understand this correlation we must refer to the fact, that short-lasting hypoxia is not associated with a rise in BNP, whereas repeating, sustaining episodes are [35]. Therefore, like shown in present study, only patients with high $\mathrm{AHI}$, therefore longer time of hypoxia are likely to present elevated BNP levels.

Another interesting finding from the present study refers to association of BNP, BMI, and obstructive apnoea-hypopnoea episodes specific for OSA. OSA prevalence is well known to be associated with increasing body mass, and BMI. In morbidly obese patients the disease is found to be approximately $90 \%$ [36]. Obesity not only exacerbates OSA, by easing the airways obstruction, but OSA itself promotes obesity. Daytime sleepiness associated with OSA predisposes patients to experience reduction physical activity, worse physical performance, and worsening of energy metabolism [20,37]. 
Contrary, despite obvious increased hemodynamic overload in obese patients, studies show that BNP levels in this group are likely to be lower than in the non-obese population. Large population data, coming in example from studies like Framingham study show negative correlation with this natriuretic peptide and body mass [38]. Similar trends are observed also in patients with cardiovascular disease, including heart failure [39]. This association is not fully resolved, but few hypotheses have been proposed to explain the issue [40]. First of all, increased peripheral clearance of natriuretic peptides has been noticed in obese patients. It is due to an increased expression of C-type natriuretic peptide receptor in fat tissue. The receptor plays role in degradation of various peptides, including BNP. Other hypothesis refers to gonadal hormones. Level of oestrogens is altered in overweight and obese patients, while oestrogens/ /androgens circulating ratio is one of the factors responsible for BNP production and excretion. Other theories refer the role of adipokines, salt retention, and ectopic fat deposits in cardiac muscle tissue [39]. Unfortunately, up to date all remain speculative and unexplained.

In the present study, contrary to abovementioned finding BNP levels rose along with the AHI score. It can be explained by the fact, that AHI parameters were closely associated also with BMI. To simplify, the fatter the patient was, the higher the AHI, and the higher the AHI, the more likely the patient was to experience persistent hypoxia, and haemodynamic overload in heart chambers. Consequences of repetitive apnoeas and hypopnoeas, include autonomic dysregulation, elevated sympathetic tone, oxidative stresses, endothelial dysfunction, atrial stretch caused, and increased intrathoracic pressure, and contribute to heart overload (in the same manner promoting atrial fibrillation) [20]. It was proven, that apnoeas and hypopnoeas associated with OSA deteriorate function of the ventricles and causes increased heart wall stress [41]. We can hypothesize that number of apnoea-hypopnoea episodes and its BNP production promoting effect overcomes the suppression coming from fat deposits, which is especially visible in patients with atrial fibrillation, who are already predisposed to have altered intracardiac haemodynamics.

\section{Conclusions}

Episodes of OSA are highly prevalent in patients with atrial fibrillation. In patients who have AHI values exceeding $\geq 15$ per hour $\mathrm{BNP}$ concentrations are higher compared to the patients who have AHI $<15$ per hour. In this group of patients, elevated BNP levels indicate that number of sleep disordered breathing episodes may be associated with extensive heart wall stretch. Also, BNP levels rise along with AHI values, irrespectively for suppressing effect of elevated BMI.

\section{Acknowledgments}

This study was supported by grants from the Polish Cardiac Society, and has not received funding or grants from pharmaceutical or other industrial corporations.

\section{References}

1. Szymanski F.M., Grabowski M., Filipiak K.J. et al. Prognostic implications of myocardial necrosis triad markers' concentration measured at admission in patients with suspected acute coronary syndrome. Am. J. Emerg. Med 2007; 25: 65-68.

2. Szymanski F.M., Karpinski G., Filipiak K.J. et al. Usefulness of the D-dimer concentration as a predictor of mortality in patients with out-of-hospital cardiac arrest. Am. J. Cardiol. 2013; 112: 467-471.

3. Piekarska M.L., Szurlej B., Latusek T., Wdowik G., Deja M.A. Postoperative serum troponin $\mathrm{T}$ concentration in patients undergoing aortic valve replacement does not predict early postoperative outcome. Kardiol. Pol. 2013; 71: 1237-1244.

4. Szymanski F.M., Grabowski M., Hrynkiewicz A., Filipiak K.J., Karpiński G., Opolski G. Usefulness of myocardial necrosis triad markers for predicting 4-year mortality in patients with suspected acute coronary syndrome. Acta Cardiol. 2008; 63: 473-477.

5. Thygesen K., Alpert J.S., Jaffe A.S., Simoons M.L., Chaitman B.R., White H.D.; Writing Group on the Joint ESC/ACCF/AHA/WHF Task Force for the Universal Definition of Myocardial Infarction, et al.; ESC Committee for Practice Guidelines (CPG). Third universal definition of myocardial infarction. Eur. Heart J. 2013; 33: 2551-2567.

6. Torbicki A., Perrier A., Konstantinides S. et al. ESC Committee for Practice Guidelines (CPG). Guidelines on the diagnosis and management of acute pulmonary embolism: the Task Force for the Diagnosis and Management of Acute Pulmonary Embolism of the European Society of Cardiology (ESC). Eur. Heart J. 2008; 29: 2276-2315.

7. McMurray J.J., Adamopoulos S., Anker S.D. et al.; ESC Committee for Practice Guidelines. ESC Guidelines for the diagnosis and treatment of acute and chronic heart failure 2012: The Task Force for the Diagnosis and Treatment of Acute and Chronic Heart Failure 2012 of the European Society of Cardiology. Developed in collaboration with the Heart Failure Association (HFA) of the ESC. Eur. Heart J. 2012; 33: 1787-1847.

8. Zdravkovic V., Mladenovic V., Colic M. et al. NT-proBNP for prognostic and diagnostic evaluation in patients with acute coronary syndromes. Kardiol. Pol. 2013; 71: 472-479.

9. Lopez-Sendon J. To BNP or not to BNP. Eur. Heart J. 2013; 34: 2498-2500.

10. Camm A.J., Kirchhof P., Lip G.Y. et al.; European Heart Rhythm Association; European Association for Cardio-Thoracic Surgery, Guidelines for the management of atrial fibrillation: the Task Force for the Management of Atrial Fibrillation of the European Society of Cardiology (ESC). Eur. Heart J. 2010; 31: 2369-2429.

11. Camm A.J., Lip G.Y., De Caterina R. et al.; ESC Committee for Practice Guidelines (CPG). 2012 focused update of the ESC Guidelines for the management of atrial fibrillation: an update of the 2010 ESC Guidelines for the management of atrial fibrillation. Developed with the special contribution of the European Heart Rhythm Association. Eur. Heart J. 2012; 33: 2719-2747. 
12. Parati G., Lombardi C., Hedner J. et al.; EU COST Action B26 members. Recommendations for the management of patients with obstructive sleep apnoea and hypertension. Eur. Respir. J. 2013; 41: 523-538.

13. Epstein L.J., Kristo D., Strollo P.J. Jr et al.; Adult Obstructive Sleep Apnea Task Force of the American Academy of Sleep Medicine. Clinical guideline for the evaluation, management and long-term care of obstructive sleep apnea in adults. J. Clin. Sleep Med. 2009; 5: 263-276.

14. Cheng V., Kazanagra R., Garcia A. et al. A rapid bedside test for B-type peptide predicts treatment outcomes in patients admitted for in patients with congestive heart failure. J. Am. Coll. Cardiol. 2001; 37: 386-391.

15. Tjeerdsma G., de Boer R.A., Boomsma F., van den Berg M.P., Pinto Y.M., van Veldhuisen D.J. Rapid bedside measurement of brain natriuretic peptide in patients with chronic heart failure. Int. J. Cardiol. 2002; 86: 143-149.

16. Stewart S., Hart C.L., Hole D.J., McMurray J.J. Population prevalence, incidence, and predictors of atrial fibrillation in the Renfrew/ /Paisley study. Heart 2001; 86: 516-521.

17. Go A.S., Hylek E.M., Phillips K.A. et al. Prevalence of diagnosed atrial fibrillation in adults: national implications for rhythm management and stroke prevention: the AnTicoagulation and Risk Factors in Atrial Fibrillation (ATRIA) Study. JAMA 2001; 285: 2370-2375.

18. Young T., Palta M., Dempsey J., Skatrud J., Weber S., Badr S. The occurrence of sleep-disordered breathing among middle-aged adults. N. Engl. J. Med. 1993; 328: 1230-1235.

19. Todd K., McIntyre W.F., Baranchuk A. Obstructive sleep apnea and atrial fibrillation. Nat. Sci. Sleep 2010; 2: 39-45.

20. Szymanski F.M., Puchalski B., Filipiak K.J. Obstructive sleep apnea, atrial fibrillation, and erectile dysfunction: are they only coexisting conditions or a new clinical syndrome? The concept of the OSAFED syndrome. Pol. Arch. Med. Wewn. 2013; 123: 701-707.

21. Vílchez J.A., Roldán V., Hernández-Romero D., Valdés M., Lip G.Y., Marín F. Biomarkers in atrial fibrillation: an overview. Int. J. Clin. Pract. 2014; 68: 434-443.

22. van den Bos E.J., Constantinescu A.A., van Domburg R.T., Akin S., Jordaens L.J., Kofflard M.J. Minor elevations in troponin I are associated with mortality and adverse cardiac events in patients with atrial fibrillation. Eur. Heart J. 2011; 32: 611-617.

23. Hijazi Z., Oldgren J., Andersson U. et al. Cardiac biomarkers are associated with an increased risk of stroke and death in patients with atrial fibrillation: a Randomized Evaluation of Long-term Anticoagulation Therapy (RE-LY) substudy. Circulation 2012; 125: 1605-1616

24. Aviles R.J., Martin D.O., Apperson-Hansen C. et al. Inflammation as a risk factor for atrial fibrillation. Circulation 2003; 108: 3006-3010.

25. Lip G.Y., Patel J.V., Hughes E., Hart R.G. High-sensitivity C-reactive protein and soluble CD40 ligand as indices of inflammation and platelet activation in 880 patients with nonvalvular atrial fibrillation: relationship to stroke risk factors, stroke risk stratification schema, and prognosis. Stroke 2007; 38: 1229-1237.
26. Conway D.S., Buggins P., Hughes E., Lip G.Y. Prognostic significance of raised plasma levels of interleukin- 6 and C-reactive protein in atrial fibrillation. Am. Heart J. 2004; 148: 462-466.

27. Hijazi Z., Oldgren J., Siegbahn A., Granger C.B., Wallentin L. Biomarkers in atrial fibrillation: a clinical review. Eur. Heart J. 2013; 34: 1475-1480.

28. Asanin M., Stankovic S., Mrdovic I. et al. B-type natriuretic peptide predicts new-onset atrial fibrillation in patients with ST-segment elevation myocardial infarction treated by primary percutaneous coronary intervention. Peptides 2012; 35: 74-77.

29. Hijazi Z., Wallentin L., Siegbahn A. et al. N-terminal pro-B-type natriuretic peptide for risk assessment in patients with atrial fibrillation: insights from the ARISTOTLE Trial (Apixaban for the Prevention of Stroke in Subjects with Atrial Fibrillation). J. Am. Coll. Cardiol. 2013; 61: 2274-2284.

30. Kita H., Ohi M., Chin K. et al. The nocturnal secretion of cardiac natriuretic pepitdes during obstructive sleep apnoea and its response to therapy with nasal continuous positive airway pressure. J. Sleep Res. 1998; 7: 199-207.

31. Kaditis A.G., Alexopoulos E.I., Hatzi F. et al. Overnight change in brain natriuretic peptide levels in children with sleep-disordered breathing. Chest 2006; 130: 1377-1384.

32. Ljunggren M., Lindahl B., Theorell-Haglöw J., Lindberg E. Association between obstructive sleep apnea and elevated levels of type B natriuretic peptide in a community-based sample of women. Sleep 2012; 35: 1521-1527.

33. Patwardhan A.A., Larson M.G., Levy D. et al. Obstructive sleep apnea and plasma natriuretic peptide levels in a community-based sample. Sleep 2006; 29: 1301-1306.

34. Svatikova A., Shamsuzzaman A.S., Wolk R., Phillips B.G., Olson L.J., Somers V.K. Plasma brain natriuretic peptide in obstructive sleep apnea. Am. J. Cardiol. 2004; 94: 529-532.

35. Gottlieb J.D., Schwartz A.R., Marshall J. et al. Hypoxia, not the frequency of sleep apnea, induces acute hemodynamic stress in patients with chronic heart failure. J. Am. Coll. Cardiol. 2009; 54: 1706-1712.

36. Lopez P.P., Stefan B., Schulman C.I., Byers P.M. Prevalence of sleep apnea in morbidly obese patients who Obesity and Obstructive Sleep Apnea 463 presented for weight loss surgery evaluation: more evidence for routine screening for obstructive sleep apnea before weight loss surgery. Am. Surg. 2008; 74: 834-838.

37. Shah N., Roux F. The relationship of obesity and obstructive sleep apnea. Clin. Chest Med. 2009; 30: 455-465.

38. Wang T.J., Larson M.G., Levy D. et al. Impact of obesity on plasma natriuretic peptide levels. Circulation 2004; 109: 594-600.

39. Iwanaga Y., Kihara Y., Niizuma S. et al. BNP in overweight and obese patients with heart failure: an analysis based on the BNP-LV diastolic wall stress relationship. J. Card. Fail. 2007; 13: 663-667.

40. Clerico A., Giannoni A., Vittorini S., Emdin M. The paradox of low BNP levels in obesity. Heart Fail. Rev. 2012; 17: 81-96.

41. Tanaka Y., Hino M., Mizuno K., Gemma A. Assessment of the relationship between right ventricular function and the severity of obstructive sleep-disordered breathing. Clin. Respir. J. 2014; 8: 142-151. 